\title{
Hysteresis, Cultural Dimensions and the Image of the Sustainability of Tourism Destinations: A Cross-Cultural Comparative Study between Brazil and the Netherlands.
}

\author{
Anderson Gomes de Souza ${ }^{1}$
}

Received: 15/03/2015

\footnotetext{
${ }^{1}$ Avenida dos Funcionários, s/n; $1^{\circ}$ andar - sala D-4, 50740-580 - Recife/PE, Brazil; tel: + 55812126 8750; email: anderson.gsouza@ufpe.br
}

Supervisors: Salomão Alencar de Farias

Marisa Paula de Brito

Institution awarding the Ph. D. Degree: Federal University of Pernambuco (UFPE - Brazil)

Date of defence: 19/12/2014

(c) 2015 Varna University of Management. All rights reserved

Citation: Souza, A. (2015) Hysteresis, Cultural Dimensions and the Image of the Sustainability of Tourism Destinations: A Cross-Cultural Comparative Study between Brazil and the Netherlands. Doctoral Dissertation Summary. European Journal of Tourism Research 11, pp. 176-180

\section{Goal and objectives of the dissertation Goal}

Image is one of the most important elements for understanding consumer behaviour in the tourism sector. Several strategies are used by managers (and tourism practitioners) to attract an increasing number of visitors to a destination, and the construction of identities based on local sustainability has been a marketing tool broadly used in this sense. Thus, the purpose of this study was to discuss how the image of the sustainability of tourism destinations can be influenced by the consumer's culture of origin, specifically cultural dimensions such as the masculinity/femininity and individualism/collectivism proposed by Hofstede (1980). Moreover, it was also suggested that the historical-affective aspect 176 that links the tourist's country of origin to the tourism place to be visited can still affect the destination image, which would characterize the occurrence of the hysteresis phenomenon in the consumption of tourism product.

\section{Objectives}

- Analyse the propensity of Brazilian and Dutch participants to behave accordingly with the principles of sustainability while on a holiday trip.

- Measure and evaluate Brazilian and Dutch participants' image regarding the sustainable aspects of certain tourism destinations.

- Investigate the existence of relations between the image of the sustainability of tourism destinations and the cultural 
dimensions of masculinity and individualism proposed by Hofstede (1980).

- Investigate the existence of relations between the image of the sustainability of tourism destinations and the historicalaffective aspect that links certain countries (hysteretic effect).

- Check whether the relations between the image of the sustainability of tourism destinations and the cultural dimensions of masculinity and individualism are modified due to the hysteresis phenomenon.

\section{Methodology}

Given that the core purpose of the study was to investigate the image of the sustainability of tourism destinations, the research strategy adopted was the analysis of two different countries in terms of cultural values: Brazil and the Netherlands. Therefore, a set of questionnaires were administered randomly during a two months period (2014) - among students of both countries. A total of 537 participants completed the self-administered instrument, of which 279 were Brazilians whereas 258 were Dutch. Moreover, once the influence of historical-affective linkage on consumers' image was also intended to be checked in this research, participants' responses were directed toward two specific tourism destinations: Portugal and South Africa. Thus, $48 \%$ of Brazilian participants expressed their opinion regarding the image they held of Portugal, while $52 \%$ analysed South Africa. On the other hand, $43 \%$ of Dutch respondents analysed Portugal, and $57 \%$ South Africa. Based on the data collected, some hypotheses were verified in the attempt to find possible relations between participants' culture of origin and the image they held of those destinations. For that purpose, an independent $t$-test was used to determine differences in the responses of Brazilian and Dutch respondents. Statistical significance was set at $p \leq 0.05$.

\section{Results}

The results indicated that cultures predominantly masculine/collectivist (represented herein by Brazil) tended to show more positive images regarding the sustainable elements of a destination - which included social, economic and environmental aspects, compared to cultures predominantly feminine/individualist (represented herein by the Netherlands). Furthermore, the image held by Brazilians regarding the aspects of sustainability of tourism destinations tended to be higher in the case of a country historical-affectively related to Brazil (in this case Portugal). The same could not be observed with regard to the Netherlands, as the image held by the Dutch did not vary significantly between Portugal and South Africa.

\section{Theoretical conclusions}

In terms of the cultural influence on the image of sustainability of tourism destinations, it was found that there is a relation between consumers' interpretation toward some sustainable aspects of distinctive settings and their own cultural background. Brazilian nationals tended to evaluate the elements of sustainability of the tourism destinations analysed in a more positive way than the Dutch nationals did. These primary results suggested that, in the tourism field, there is a greater likelihood for consumers to value what provides them with new experiences and sets them free from daily responsibilities. This can be regarded as the sense of novelty and escapism, inherent to the sector. Moreover, with regard to the historical-affective linkage between the countries studied, it was found that the image held by Brazilians toward the sustainability of Portugal, as a tourism destination, tended to be more positive than that of South Africa. The same conclusion could not be drawn from the responses of Dutch participants. Data analysis led to no significant variation between the Dutch nationals' image toward the sustainability of Portugal and South Africa. These results indicate the need for further investigations on the role of hysteresis with regard to the image of historical-affectively related countries. As advocated by Kastenholz (2010), consumers would tend to evaluate in a more positive way the image of those tourism destinations to which their own country of origin is historically related. However, the outcomes of this research suggested that not only the historical-affective aspect should be taken 
Hysteresis, Cultural Dimensions and the Image of the Sustainability of Tourism Destinations: A Cross-Cultural Comparative Study between Brazil and the Netherlands. Doctoral Dissertation Summary.

into consideration in this matter, but also the position occupied by those countries during their colonial period. In other words, the 'direction of the power' might explain in a greater way the impact of hysteresis on the interpretation of certain aspects of a tourism destination, such as the sustainability.

\section{Practical application of the dissertation}

According to Mackay and Fesenmaier (2000), there is a tendency - on the part of tourism destination managers and practitioners - to apply the same commercial stimulus indiscriminately to attract new consumers, from different potential outbound markets, to a certain setting. By doing so, they fail to consider certain particularities that customers' culture of origin may have and how this can impact on the choice of a destination. However, this research showed that different cultures interpret the phenomenon of sustainability differently, especially when they are connected historical-affectively to the location. Therefore, marketing and communication strategies in the tourism sector should be planned so that messages are created in accordance with potential tourist's own cultural values. In other words, tourism communications must be 'culturally tailored'. That points to the need for rethinking tourism product promotions, particularly when it comes to an international trading scenario perspective.

\section{Content of the dissertation}

Abstract of chapter one - Sustainability

Sustainability began to be systematically discussed within the academic field in the 70 's. The first studies appeared in order to address some issues related to the impact of human actions on the environment and, immediately after, it became the object of interest for different study fields such as economics and humanistic perspectives.

Despite the broad literature on issues related to sustainability, there is still a lack of studies aiming at investigating it deeply in association with aspects such as the cultural values. This limitation has prevented the advance of important discussions in certain research fields. Most of the studies in the tourism field, for example, have exclusively been concerned with describing some of the sector's main impacts on the economy, society and environment. However, those researches neglect the role of social culture as a basic element, or yet a starting point, to better understand the factors that result in (non)consonant behaviours according to the principles of sustainability (Milbrath, 1984).

\section{Abstract of chapter two - Values and Culture}

Values are fundamental elements that are part of any society. In values one can find the most important clues to understand human behaviour in regard to various aspects of everyday life (Hofstede, 1980). Rokeach (1972) suggests that values epitomize the greatest expression that certain behaviour is preferable over others. Thus, it is quite unlikely that in a state of social stability, the members of a community act in a way contrary to that expected by the group.

In 1980 Hofstede proposed the classification of cultures according to some dimensions, which could explain and predict social behaviour. Classifying cultures in reference to particular discrepancies present in their own values represented the attempt to turn cultural aspects into constant elements subject to objective assessment. For that, the unit of analysis chosen by Hosfede (1980) to understand social conduct was the national cultures by arguing that countries were the clearest representation of cultural unity.

\section{Abstract of chapter three - Masculinity/ Femininity Cultural Dimension}

Masculinity/femininity dimension is basically grounded on the assumption that the core question to access human behaviour through a cultural perspective is by understanding the direction of an individual's goals. It is assumed that in predominantly masculine societies much of the members' actions are usually oriented to personal interests over the social common sense itself. On the other hand, it is believed that in social groups where feminine values prevail, there seems to be a greater likelihood that individuals' behaviour aims at the society welfare as a 
whole instead of personal gains (Hofstede, 1980; Hofstede, 2001; Mooij, 2010).

\section{Abstract of chapter four - Individualism/ Collectivist Cultural Dimension}

Hofstede (2001) defines the individualism/ collectivism dimension as the clearest representation of the individuals' dependence on certain social groups to which they belong. This conception means that, within individualistic societies, people tend to be oriented to an independent life in which one usually must look after himself/herself and, to some extent, his/her immediate relatives. On the contrary, collectivism is related to extended dependence ties demanding individual's behaviour to be subject to approval by the other members of a group. Thereby, it is believed that the excessive subjection linkages existing in this particular type of grouping lead to a high level of dependence between individuals in regard to several aspects of everyday life. Early (1989) states that probably the social collectivism might be connected to one's transferring of responsibilities to others, which could cause the individuals to become less proactive about certain social issues.

\section{Abstract of chapter five - Tourism Destination Image}

Just like sustainability, the concept of image of tourism destinations was inserted into the academic studies in the early 70's and, since then, has proven to be one of the most explored constructs in tourism literature. Over the last four decades, scholars have sought to clearly understand the real impact of the consumers' (tourists) perception toward destinations on the decision making process.

Nevertheless, as stated by Pike (2002), over the past decades much of the research developed on tourism image literature has aimed at applying the acquired knowledge to specific aspects of travel context. The main approach employed though, has been the assessment of individual's impressions towards certain locations, without attempting to establish comparisons among the findings in different destinations. Thereby, some of these results might have neglected important insights about the possible variance in destinations' image due to factors such as cultural values.

Abstract of chapter six - Hysteresis and the Historical-Affective Aspect of Consumption in Tourism

Daniela and lon-Danut (2013) emphasize that Nicholas Georgescu-Roegen (1971) was responsible for popularizing the term 'hysteresis' - by presenting its possible applications for the consumption field - in his paper entitled 'The entropy law and the economic process'. It is remarkable that for the very first time the importance of the past relations between countries could be discussed on the basis of social sciences perspective. That, in turn, led scholars - such as Sirgy and Su (2000) - to propose that the impact of past relations involving different cultures should be considered an important factor to understand consumer behaviour in the tourism industry. As stated by Kastenholz (2010), it is quite possible that potential tourists identify themselves better with those destinations linked historical-affectively to their own culture.

\section{References:}

Daniela, M., Ion-Danut, J. (2013) Consumer behaviour: does history matter. Revista Economica 65(1), 121-128.

Early, P. (1989) Social loafing and collectivism: a comparison of the United States and the People's Republic of China. Administrative Science Quarterly 34(4), 565-581.

Hofstede, G. (2001) Culture's consequences: comparing values, behaviors, institutions, and organizations across nations. California: Thousand Oaks.

Hofstede, G. (1980) Culture's consequences: international differences in workrelated values. Beverly-Hills: Sage.

Kastenholz, E. (2010) Cultural proximity as a determinant of destination image. Journal of Vacation Marketing 16(4), 313-322.

Mackay, K., Fesenmaier, D. (2000) An exploration of cross-cultural destination image assessment. 
Hysteresis, Cultural Dimensions and the Image of the Sustainability of Tourism Destinations: A Cross-Cultural Comparative Study between Brazil and the Netherlands. Doctoral Dissertation Summary.

Journal of Travel Research 38, 417423.

Milbrath, L. (1984) A proposed value structure for a sustainable society. The Environmentalist 4(2), 113-124.

Mooij, M. (2014) Global marketing and advertising: understanding cultural paradoxes. 4.ed. Thousand Oaks: SAGE.
Pike, S. (2002) Destination image analysis a review of 142 papers from 1973 to 2000. Tourism Management 23(5), 541-549.

Rokeach, M. (1972) Beliefs, attitudes and values: a theory of organization and change. San Francisco: Jossey-Bass.

Sirgy, M., Su, C. (2000) Destination image, self-congruity, and travel behavior: toward an integrated model. Journal of Travel Research $38,340-352$. 